\title{
Environmental Risk Factors for Parkinson's Disease: The Epidemiologic Evidence
}

\author{
Bruce S. Schoenberg*
}

\begin{abstract}
Descriptive data from several studies suggest variations in the frequency of Parkinson's disease in different population groups. Door-to-door surveys were carried out among a biracial U.S. population (blacks and whites) and in communities in Nigeria and the People's Republic of China. The U.S. investigation revealed no substantial differences in the age-adjusted prevalence ratios by race. However, blacks in Nigeria have a much lower prevalence ratio than blacks in the U.S., suggesting an environmental etiologic factor. Prevalence ratios derived from China are also lower than the U.S. figures. Studies of temporal trends in the incidence rates in one U.S. population (Rochester, Minnesota) show virtually no change over 35 years, indicating that the primary cause(s) of Parkinson's disease must have been present in this nonindustrialized community for many years. Analytic studies generally reveal an inverse association between Parkinson's disease and cigarette smoking, although epidemiologic evidence does not support a direct protective effect of smoking. Preliminary investigations suggest an increased risk associated with the rural environment and the consumption of well water. Further studies are required to discover as yet unknown environmental factors that heighten the risk of Parkinson's disease.
\end{abstract}

\begin{abstract}
RÉSUMÉ: Facteurs de risque environnementaux dans la maladie de Parkinson: donnéesépidémiologiques. Des données descriptives provenant de plusieurs études suggèrent qu'il existe des variations dans la fréquence de la maladie de Parkinson dans différents groupes de population. Des enquêtes porte-à-porte ont été effectuées, utilisant les même démarches de recrutement des cas et de diagnostique, parmi une population américaine comprenant des individus de races blanche et noire, et dans des localités du Nigeria et de la République Populaire de Chine. L'étude américaine n'a révélé aucune différence substantielle dans la proportion de prévalence par race, ajustée pour l'âge. Cependant les noirs du Nigeria ont une proportion de prévalence beaucoup plus basse que les noirs américains, suggérant un facteur étiologique environnemental. Les proportions de prévalence émanant de Chine sont aussi plus basses que les chiffres américains. L'étude des tendances à travers le temps des taux d'incidence dans une population américaine (Rochester, Minnesota) ne montre virtuellement pas de changement sur une période de 35 ans, indiquant que la(les) cause(s) primaire(s) de la maladie de Parkinson doive(nt) avoir été présente(s) dans cette localité non industrialisée depuis plusieurs années. Des études analytiques révèlent en général une association inverse de la maladie de Parkinson avec le tabagisme, même si les observations épidémiologiques ne viennent pas étayer un effet protecteur direct du tabagisme. Des études préliminaires suggèrent un risque accru associé à l'environnement rural et à la consommation d'eau de puits. Des études supplémentaires sont nécessaires pour découvrir des facteurs environnementaux encore inconnus qui augmentent le risque d'être atteint de la maladie de Parkinson.
\end{abstract}

Can. J. Neurol. Sci. 1987; 14:407-413

\section{Epidemiologic Methods Applied to Parkinson's Disease}

Neuroepidemiology may be defined as the study of the distribution and dynamics of neurologic diseases in human populations and the factors that affect those characteristics. ' Whereas the clinician focuses on the individual patient, the neuroepidemiologist is concerned with the occurrence of neurologic disease in the entire community. Investigations of the distribution of disease involve identifying the particular segments of the population affected. For example, does the disease occur more often in women or among the elderly? Investigations of the dynamics of disease address the question of whether the disease is changing over time. Is it increasing or decreasing? Are the clinical manifestations changing?

The patterns of disease in the community, as derived from descriptive epidemiologic studies, provide important information for formulating etiologic hypotheses. Thus, if the incidence of a given disease has remained stable over several decades, we must search for a cause which has been present in the environment of the community for a considerable period of time.

The two most important considerations for the neuroepidemiologist are the representativeness of the population selected 
for investigation and the accuracy of the diagnoses in that population.

On the basis of their experience, clinicians review patients' signs and symptoms, establish a diagnosis and a prognosis, and institute appropriate forms of therapy. But how representative is the physician's personal experience? This is a critical concern for the epidemiologist. Certain physicians practicing in the community may specialize in movement disorders, whereas other clinicians in the same community may rarely treat such patients. Because of a lack of financial resources and limited access to neurologic expertise, some individuals with the disease of interest may never seek medical care or may never be correctly diagnosed. The situation is analogous to blind-folded men examining different parts of an elephant, with each coming to an entirely different conclusion as to the characteristics of the beast. To avoid this problem, the neuroepidemiologist attempts to identify all cases of a particular neurologic disease in a well-defined population. In drawing conclusions from investigating disease occurrence in a population, one must know the characteristics of that population. One might arrive at very different conclusions by examining residents of a retirement community, as contrasted with inhabitants of a military base. One must therefore be certain that the community which has been studied is representative of the larger population to which you wish to generalize the results.

Of equal importance is the problem of diagnostic accuracy. The results of the most sophisticated analysis are no better than the quality of the original data. The greater the accuracy and completeness of the physician's observations and descriptions, the greater the validity of the epidemiologic information concerning the spectrum of disease in the population under investigation. If residents of a community have little or no access to physicians with neurologic expertise, then it may be necessary to have a neurologist review all suspected cases. In comparing the results of several different studies, it is important to consider the criteria for making a diagnosis. Some investigations simply accept the diagnosis made by a physician. Other surveys set up strict criteria (e.g., to make a diagnosis of parkinsonism, the patient must exhibit a resting tremor, rigidity, and bradykinesia). It is also important to note the criteria employed todistinguish secondary parkinsonism from Parkinson's disease (idiopathic parkinsonism).

The magnitude of the disease burden in the community is usually expressed in terms of the population at risk. To say how many people had or died of a particular disease has little meaning unless one also states how many people were at risk of having or dying from that specific disease. To adjust for this, the epidemiologist usually expresses disease magnitude as a rate or ratio, in which the frequency of disease (numerator) is related to the population at risk of having disease (denominator). The magnitude of the disease burden in the population is usually defined in terms of certain epidemiologic indices, such as mortality, prevalence, and incidence.'

Epidemiologic studies of Parkinson's disease pose some special problems. The parkinsonian syndrome can result from tumors or other focal lesions of the basal ganglia; as a sequela to von Economo's type A encephalitis; from exposure to certain toxins, such as manganese or carbon monoxide; or following the use of pharmacologic agents such as phenothiazines. It may be difficult in evaluating all cases in a community to distinguish between secondary parkinsonism and Parkinson's disease. Stud- ies of the incidence of Parkinson's disease require an accurate determination of disease onset. This may be impossible when the signs and symptoms develop insidiously. Parkinson's disease occurs primarily among the elderly. Careful evaluation may be required to distinguish the characteristic features of Parkinson's disease from other signs observed in the elderly patient (e.g., essential tremor or a general slowing and hesitancy of movement due to the pain and stiffness of arthritis). This problem is compounded by the fact that often we do not have adequate data concerning the functional neurologic status of older individuals without diseases of the nervous system. The concept of what defines "normal" must be carefully reconsidered. Patients in this age group are often afflicted by multiple disorders, and sorting out the specific cause of disability may be a formidable task. Finally, we must consider the patient's accessibility to and desire to utilize expert neurologic care. The elderly patient or his family may feel that tremor and a slowness of movement and difficulty walking are part of the aging process and may not seek medical care. Hence, a correct diagnosis is never established.

\section{Descriptive Studies}

\section{Mortality Data}

Mortality tabulations have a number of advantages, in that they are readily available for many countries and provide information concerning large populations over many years. ' Unfortunately, when dealing with Parkinson's disease, mortality data do not adequately reflect the frequency of the disorder. Although the disease may be listed on the death certificate, some other condition is often specified as the single, underlying cause of death. In fact, if we tabulate the number of times Parkinson's disease appears anywhere on U.S. death certificates and compare it to the number of times it is listed as the underlying cause of death, the former figure is nearly four times greater than the latter figure. ${ }^{2}$ Another difficulty is the accuracy of the diagnoses appearing on the death certificate. Despite these deficiencies, interesting patterns emerge when analyzing data from the U.S. ${ }^{2}$ The mortality rates are negligible for people under age 45 . When considering only the underlying cause of death, the rates increase steadily with advancing age, reaching a peak at ages 75 through 84 , and then declining among the oldest age group. If one bases the tabulations on all listings of Parkinson's disease on U.S. death certificates, the mortality rates continue to increase with advancing age. Another interesting observation is that Parkinson's disease death rates for the U.S. and for England and Wales have remained relatively stable over time. ${ }^{3,4}$

\section{Prevalence Data}

Morbidity information is much more difficult to obtain, since such data require special surveys. There have been several studies providing estimates of the prevalence of parkinsonism in general or Parkinson's disease in particular. A number of different and innovative approaches have been employed to try to identify all cases within the community. These include searches of existing medical records, the use of a records-linkage system, data derived from medical insurance statistics, estimates based on sales of levodopa and related compounds, and direct measures of prevalence utilizing door-to-door survey techniques. ${ }^{5}$ One can use medical records as the sole method of case ascertainment only if: a) those with signs or symptoms have suffi- 
cient motivation and resources to seek medical care; b) neurologic expertise is readily available to members of the community; c) uniform diagnostic criteria are utilized to establish the diagnosis; and d) sufficient detail is available in the medical record to allow for retrospective review. If the diagnosis is uncertain in some instances, it may be necessary for the neurologist to reexamine these selected cases. In situations in which these criteria are not fulfilled, it is necessary to use door-to-door survey techniques to identify all cases of Parkinson's disease within the community.

Selected findings from several studies are summarized in Table 1. Because of the change in prevalence ratios with age, it is important that any comparisons utilize age-specific or ageadjusted figures. The different surveys reported in Table 1 employed different methods of case identification and should be compared with caution. For example, the rather high prevalence ratios reported for Rochester, Minnesota, probably reflect a very high level of case ascertainment. In rather unique circumstances that exist for residents of Rochester, Minnesota, it is possible to obtain accurate statistics by applying defined diagnostic criteria to information available in medical records. By means of a records-linkage system, data concerning all medical contacts (i.e., outpatient records, inpatient records, house calls, emergency room visits, etc.) are kept together in a single computerized file. ${ }^{17.18}$ Furthermore, the population has easy access to expertise in neurologic diagnosis and this access is not generally limited because of a lack of financial resources. Finally, the medical records contain sufficient details concerning the findings of the medical history, the physical examination, and the results of laboratory tests to allow retrospective review of the diagnosis. Only in such special instances, is it possible to rely on medical records to identify most or all of the cases within a community. Another mechanism useful in attaining a high level of case ascertainment is to employ a door-to-door survey approach. This requires an instrument that is sensitive in detecting those likely to have Parkinson's disease and requires the cooperation of the population being studied. This procedure

Table 1. Prevalence ratios of Parkinson's disease from selected studies $\frac{\text { Cases per 100,000 }}{\text { Age- }}$ adjusted to 1960 US

Area

Gothenburg, Sweden ${ }^{6}$ Carlisle, England ${ }^{7}$ Iceland $^{8}$

Rochester, Minnesota ${ }^{9}$ Gippsland, Victoria, Australia ${ }^{10}$ Southwest Finland ${ }^{11}$

Baltimore, Maryland ${ }^{12}$

Whites

Blacks

Copiah County, Mississippi ${ }^{13}$ Whites

Blacks

Yonago, Japan ${ }^{14}$

Six cities, People's Republic of China ${ }^{15}$

* Data from reference 16.

+ Calculated from data given in the corresponding published report. The table is reproduced in modified form from Kessler, 1978. ${ }^{16}$ has been successfully employed in investigations conducted in rural, biracial Copiah County, Mississippi, U.S.A. ${ }^{13}$ and in urban areas of the People's Republic of China. ${ }^{15}$

Based on earlier studies carried out in Baltimore, Maryland, on cases coming to medical attention, it appeared that Parkinson's disease is much more prevalent among whites as compared to blacks (Table 1). ${ }^{12.16}$ However, because of a concern that whites and blacks might not have availed themselves of medical services to the same extent, this reported racial difference in prevalence ratios was tested in a door-to-door survey of all residents of a biracial county in the southern part of the U.S. In contrast to the Baltimore findings, the results of the door-todoor survey in Mississippi revealed virtually no differences in the age-adjusted prevalence ratios of Parkinson's disease among blacks and whites residing in Copiah County (Table 1). Of particular interest is that $32 \%$ of the cases among whites and $58 \%$ of the cases among blacks were newly diagnosed at the time of the survey. ${ }^{13}$ These cases would have been missed in an investigation relying on medical records or previously established physician diagnoses. A similar procedure was carried out among a sample population of 63,195 in six urban centers of the People's Republic of China, yielding much lower prevalence ratios (Table 1). ${ }^{15}$ Most recently, the same approach was utilized in the community of Igbo-Ora, Nigeria, among a black population of West Africa. ${ }^{19}$ In a population of 3,412 over age 39 in this community, there were two cases of Parkinson's disease, yielding a prevalence ratio 59/100,000. The comparable figures among the surveyed rural black U.S. population were: number of people over age $39=3,521$; cases of Parkinson's disease $=12$; prevalence ratio $=341 / 100,000$. To adjust for differences in the age distribution of the communities involved in the U.S. and Nigerian investigations, age-specific prevalence ratios from the U.S. study were applied to the Igbo-Ora population: 10.3 cases would be expected; only 2 cases were observed. Osuntokun and his colleagues ${ }^{19}$ believe the differences in prevalence figures are too large to be explained by possible variations in survival between those with Parkinson's disease in Africa and the U.S. and that the variation probably reflects a difference in incidence rates. The finding is consistent with the hypothesis that an environmental agent(s) may be responsible for the observed differences. The same techniques are now being employed in India and various South American countries. ${ }^{20,21}$

Using rough measures of prevalence, some investigators have attempted to correlate the geographic distribution of Parkinson's disease with exposure to a putative etiologic agent. For example, Barbeau and colleagues reported an uneven distribution in the prevalence ratios of Parkinson's disease in Quebec and correlated this pattern with the use and sale of pesticides. ${ }^{22.23}$ They employed estimates of prevalence based on death certificates, government insurance statistics, sales of levodopa, and cases known to neurologists. In another study of the prevalence ratios of Parkinson's disease in counties of Sweden, de Pedro Cuesta reported high figures for Gavleborg County and related this result to the deposition of heavy metals (particularly chromium) in this region. The Swedish prevalence figures were derived from levodopa sales. ${ }^{5}$ Each of these methods has serious possible problems in terms of diagnostic accuracy and the level of case ascertainment, however, and more careful measures of prevalence are required to confirm these interesting findings. 
The age-specific prevalence ratios for Parkinson's disease generally show consistently increasing figures with increasing age (Figure 1). This pattern is consistent with the hypothesis advanced by Calne and Langston that Parkinson's disease may represent the effect of exposure to a toxic agent in conjunction with a reduction in the number of dopaminergic neurons with aging. ${ }^{24}$

As standardized methods and diagnostic criteria are implemented throughout the world, we shall obtain more accurate information on the actual international distribution of Parkinson's disease. These data could provide valuable etiologic clues.

\section{Incidence Data}

Incidence rates from several investigations are summarized in Table 2. Since incidence rates for Parkinson's disease vary greatly with age, it is important to use age-specific or ageadjusted figures in any comparison. Incidence rates derived from surveys with good case ascertainment provide figures near 20 new cases/100,000/year. After age 30 to 40 , the incidence rates increase with age to reach a maximum at about age 75 , with a decline in the rate of new cases after that. It may be that very elderly people who first develop signs of parkinsonism do not seek expert medical care for their condition, and hence are not correctly diagnosed. A further problem with calculating incidence data is that an accurate determination of disease onset is required. This may be extremely difficult with a condition such as Parkinson's disease. The actual shape of the age-specific incidence curve is of more than academic interest, since it has important etiologic implications. If the incidence rates rise to a maximum at a specific age and then decline, it could mean that the number of susceptible individuals at that

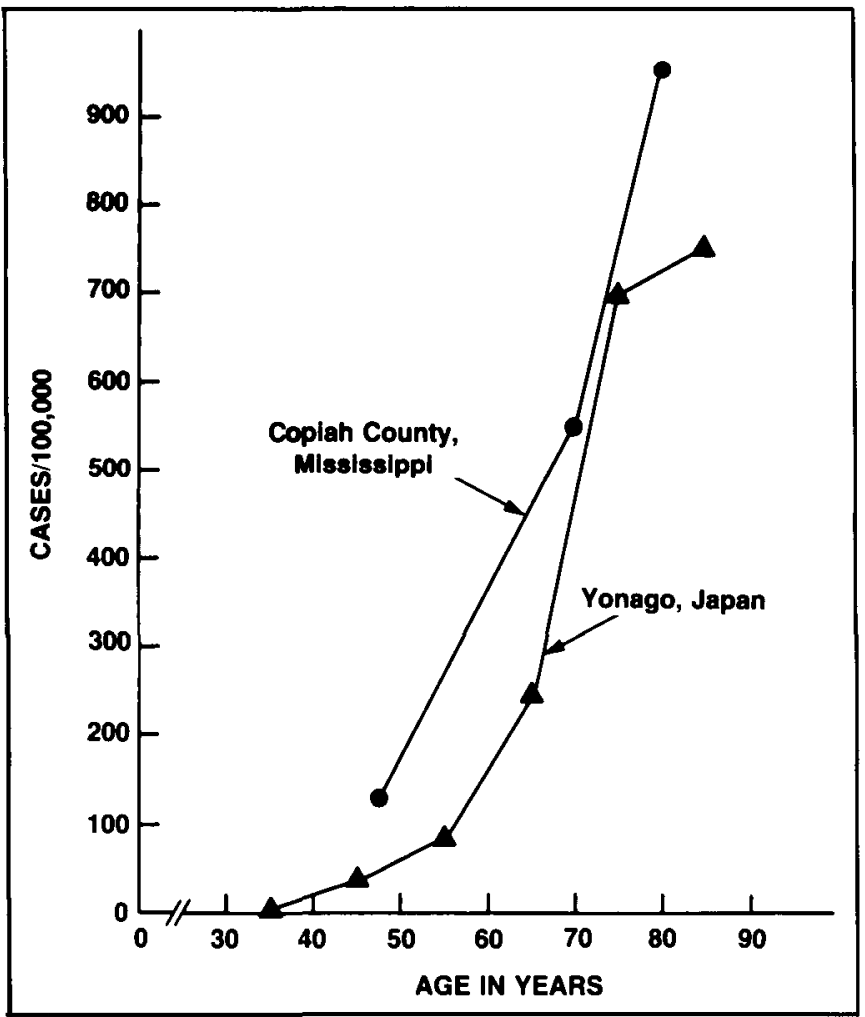

Figure I - Age-specific prevalence ratios of Parkinson's diseasefrom Copiah County, Mississippi, U.S.A.. ${ }^{13}$ and Yonago. Japan. ${ }^{14}$ age is beginning to decrease or that susceptible individuals are exposed to a putative etiologic agent for a limited number of years.

Of particular interest are incidence rates based on studies of a stable population in the United States (Rochester, Minnesota) covering a 35 -year period. ${ }^{25.26}$ From 1945 through 1979 the rates varied within the narrow range of 16 through 21 new cases $/ 100,000 /$ year, with no general trend showing either a consistent increase or decrease over time. Furthermore, wherever morbidity surveys of Parkinson's disease have been carried out, Rochester, Minnesota has one of the highest reported incidence rates (probably reflecting an excellent level of case ascertainment). These data imply that whatever causes Parkinson's disease must have been present in the nonindustrialized environment of Rochester at a fairly steady level over a period of some 35 years.

\section{Analytic Studies: Risk Factors}

On the basis of descriptive studies of the distribution of Parkinson's disease, it is possible to formulate hypotheses concerning the causation of disease. For example the stable incidence rates demonstrated for the population of Rochester, Minnesota, suggest that whatever causes Parkinson's disease must have been present in this community for a considerable period of time. Such hypotheses can be formally tested using the techniques of analytic epidemiology, which is primarily aimed at identifying factors that are associated with either a high or a low risk of disease. The study of the occurrence of natural experiments is the domain of this area of epidemiology. During the course of our lives, different individuals are exposed to a variety of different factors or conditions, some of which may play an important role in the occurrence of disease. There are two general approaches to this type of study: case-control and prospective.'

With a case-control investigation, one begins with a group of individuals who have the disease of interest (cases) and a group of individuals without the disease (controls). One then explores the present characteristics (in a cross-sectional study) or the history (in a retrospective study) of these two groups for the presence or absence of factors thought to be related to the occurrence of the disease. Obviously, one looks for factors that are distributed differentially among the cases as compared to the controls. In order to evaluate a possible association between a particular disease and a particular attribute, it is always

Table 2. Average annual incidence rates for Parkinson's disease from selected studies

\begin{tabular}{|c|c|c|c|}
\hline \multirow[b]{2}{*}{ Area } & \multirow[b]{2}{*}{ Time period } & \multicolumn{2}{|c|}{$\begin{array}{c}\text { New cases } \\
\text { per } 100,000 \text { per year } \\
\end{array}$} \\
\hline & & Observed & $\begin{array}{c}\text { Age- } \\
\text { adjusted } \\
\text { to } 1960 \mathrm{US} \\
\text { population }\end{array}$ \\
\hline Rochester, Minnesota ${ }^{9.25}$ & $\begin{array}{l}1955-66 \\
1967-79\end{array}$ & $\begin{array}{l}19.3 \\
19.7+\end{array}$ & $\begin{array}{l}17.9^{*} \\
18.6+\end{array}$ \\
\hline Carlisle, England $^{7}$ & $1955-61$ & 12.1 & $9.4^{*}$ \\
\hline lceland ${ }^{8}$ & $1954-63$ & 16.0 & $18.2^{*}$ \\
\hline Gippsland, Victoria, Australia ${ }^{10}$ & $1959-64$ & 7.0 & $7.7^{*}$ \\
\hline Southwest Finland"i & $1968-70$ & 14.8 & $11.6^{*}$ \\
\hline
\end{tabular}

\footnotetext{
* Data from reference 16.

+ Includes drug-induced parkinsonism.

The table is reproduced in modified form from Kessler 1978. ${ }^{16}$
} 
necessary to have a control group against which to compare this association.

With the prospective approach, we begin with a group or cohort exposed to a particular factor(s) and a group not exposed to the specific factor(s). The two groups are observed over time to see how many in each group develop the disease under investigation. The frequency of disease in the cohort exposed to the factor is compared to the frequency in the unexposed cohort.

Since case-control studies provide information relatively quickly and at much lower cost than the prospective approach, most analytic investigations of Parkinson's disease have used the case-control design. In analyzing the results of analytic epidemiologic studies, we must always consider whether the results are artifactual (i.e., due to differences between the groups other than the factor(s) being studied) and whether the findings are statistically significant (i.e., the possibility that the findings occurred simply on the basis of chance). It is also important to remember that an association should not be equated with the cause of the disease. A particular characteristic may be only indirectly related to a biologically significant factor. However, there are a number of features of epidemiologic associations that suggest causal inferences. For example, one must consider whether the disease appears to follow exposure to a given agent after an appropriate period of time consistent with current knowledge concerning the latency of the agent's known effects. One must also consider the strength of the association and whether exposure to the given agent appears to lead to the specific neurologic disease of interest. If the link between a given factor and a specific disease is consistent with available knowledge of pathogenesis (i.e., there is a plausible biologic explanation as to how the factor can cause the disease), the possible etiologic role of the factor is more likely. In addition, one must examine the results of multiple studies to verify the consistency of a reported association. Finally, it should be emphasized that determining the pathogenetic mechanism by which a disease is produced should also not be equated with cause. There may be multiple agents in the environment, exposure to any of which can result in the same derangement of cellular metabolism and the same clinical manifestations. We must therefore combine data derived from clinical, laboratory, and population studies in order to determine the cause(s) of a specific disease. These principles have been applied in several analytic investigations of Parkinson's disease.

Results from prospective studies of the relationship between smoking and mortality from various chronic diseases yielded some unexpected findings: mortality from Parkinson's disease was inversely associated with smoking. ${ }^{27.28}$ This finding has since been confirmed in a series of case-control investigations. ${ }^{29-35}$ Only one case-control study to date has failed to demonstrate this inverse association. ${ }^{36}$ This last investigation was based on whatever information on smoking was available in medical records. Unfortunately, such data are not obtained in a standard and uniform manner in medical histories for residents of Rochester, Minnesota, where the study was conducted. While some have suggested that a substance in cigarette smoke may provide a protective effect against Parkinson's disease, ${ }^{16}$ this is not consistent with descriptive epidemiologic patterns. Although smoking habits in the U.S. have been changing dramatically over the past $40-50$ years, available statistics on the incidence of Parkinson's disease indicate stable rates over time..$^{25.26}$
Another interesting observation involves the premorbid personality of those with Parkinson's disease ${ }^{37}$ This question has only recently been addressed in case-control studies because of the difficulties in reliably measuring the premorbid personality. A case-control study of twin pairs discordant for Parkinson's disease indicated that the affected twin tended to be more "introverted" and "self-controlled".34.38

Although several studies have suggested the importance of genetic factors in the pathogenesis of Parkinson's disease, the low concordance rates among monozygotic twins implies that heredity plays a minor role. ${ }^{34.38 .39}$ Attention has therefore focused on possible environmental factors. In a study of patients with Parkinson's disease with onset before age 41 in Saskatchewan, Canada, Rajput et al. ${ }^{40}$ found such cases occurred in rural areas more often than expected and that the cases used underground (well) water. They hypothesized that some agent in the water may be responsible for Parkinson's disease. Similar results were reported from a study based on experience from a medical center in Chicago. ${ }^{41}$ The findings of these two investigations await confirmation.

Other research has focused on a possible viral etiology of Parkinson's disease. Studies demonstrated a positive relationship between antibodies against herpes simplex virus and Parkinson's disease. ${ }^{42,43}$ Attempts to detect nucleic acid homologies to herpes simplex virus in brain tissue were not able to confirm the association, however. ${ }^{44} \mathrm{~A}$ recently reported casecontrol study of a possible relationship between childhood infections and Parkinson's disease was based on the experience of a cohort of college graduates. A statistically significant reduced risk of Parkinson's disease was associated with a history of measles before entrance to college. ${ }^{45}$ However, the diagnoses of Parkinson's disease in this investigation were based on death certificates or responses to a mailed questionnaire.

Others have reported an association between Parkinson's disease and a past history of encephalitis. ${ }^{12,46}$ Based on the increasing age of cases seen at a given medical institution, Poskanzer and Schwab ${ }^{47}$ hypothesized that the majority of cases were the result of a prior epidemic of encephalitis lethargica. This led them to predict a decline in the incidence of new cases. Stable incidence rates from Rochester, Minnesota, contradict this theory, however. ${ }^{4.25}$ Furthermore, the proportion of cases classifiable as "postencephalitic" has been declining among the Rochester, Minnesota population. ${ }^{25}$

Several other putative environmental risk factors have also been investigated. For example, one report described a much greater than expected prevalence of Parkinson's disease among a group of patients with essential tremor. ${ }^{48}$ Others have reported an inverse relationship between arterial hypertension and Parkinson's disease. ${ }^{46}$ Another investigation examined the possible relationship between various neoplasms and Parkinson's disease. Although there was an overall lower than expected frequency of cancer among those with Parkinson's disease, there apeared to be an increased risk of thyroid tumors (both benign and malignant) and malignant melanoma. The malignant melanoma was thought to be a consequence of levodopa therapy. ${ }^{49}$

With regard to other conditions, head trauma has been positively associated with Parkinson's disease, ${ }^{50}$ while vascular disease in general appears to be inversely related ${ }^{12.50}$ (a finding consistent with data for arterial hypertension). ${ }^{46}$

One group of investigators has reported an increased risk of Parkinson's disease among the relatives of cases. ${ }^{50}$ However, 
familial aggregation does not necessarily imply a genetic mechanism. It should be emphasized that families generally share the same environment, and that exogenous etiologic factors can also result in the clustering of cases within families.

Other factors that have been studied for a possible relationship with Parkinson's disease include a previous history of vaccinations, exposures to specific drugs or anesthetic agents, birth order, birth weight, alcohol consumption, coffee consumption, etc. These investigations have not produced consistent and reproducible findings, however. ${ }^{38}$

The discovery that 1-methyl-4-phenyl-1,2,3,6-tetrahydropyridine (MPTP) can produce a disorder which simulates the clinical features of Parkinson's disease ${ }^{51}$ has led to renewed interest in the possible role of neurotoxins in the pathogenesis of Parkinson's disease. ${ }^{24.52}$ Based on their findings of a possible association between pesticide use and the frequency of Parkinson's disease, ${ }^{22.23}$ Barbeau and his colleagues searched for a genetically-determined factor that might increase susceptibility to an exogenous toxin. They found an increased frequency of a hydroxylation defect for the compound debrisoquine, among Parkinson's disease cases as compared to controls. ${ }^{53}$

The stability of the incidence rates in Rochester, Minnesota, would argue against a major etiologic role for a newly introduced toxin, however ${ }^{54}$ Other case-control studies have investigated exposure to potential neurotoxins, but have failed to demonstrate any significant associations. ${ }^{38}$ Similarly, although manganese intoxication is a recognized cause of parkinsonism, it has not been implicated as a major cause in analytic investigations. ${ }^{4.38}$

Further case-control studies are being conducted in an attempt to discover as yet unrecognized factors associated with an increased risk of Parkinson's disease. Findings of such studies will hopefully provide much needed information for the development of prevention strategies for this major public health problem.

\section{REFERENCES}

1. Schoenberg BS. Principles of neurological epidemiology. In: Schoenberg BS, ed. Advances in Neurology, vol. 19, Neurological Epidemiology: Principles and Clinical Applications. New York: Raven Press, 1978: 11-54.

2. Chandra V, Bharucha NE, Schoenberg BS. Mortality data for the U.S. for deaths due to and related to twenty neurologic diseases. Neuroepidemiology 1984: 3: 149-168.

3. Duvoisin RC, Schweitzer MD. Paralysis agitans mortality in England and Wales, 1855-1962. Br J Prev Med 1966; 20: 27-33.

4. Kurtzke JF, Kurland LT. The epidemiology of neurologic disease. In: Baker AB, Baker LH, eds. Clinical Neurology, vol. 4, chapter 66. Philadelphia: Harper and Row, 1983: 55-60.

5. de Pedro Cuesta J. Thesis: Studies on the Prevalence of Paralysis Agitans by Tracer Methodology. Huddinge, Sweden: Karolinska Institute, 1986: 19-84.

6. Broman T. Parkinson's syndrome, prevalence and incidence in Goteborg. Acta Neurol Scand 1963; 39. Suppl. 4: 95-101.

7. Brewis M, Poskanzer DC, Rolland C, et al. Neurological disease in an English city. Acta Neurol Scand 1966; 42, Suppl. 24

8. Gudmundsson KR. A clinical survey of parkinsonism in Iceland. Acta Neurol Scand 1967; 43. Suppl. 33: 9-61.

9. Kurland LT, Hauser WA, Okazaki H, et al. Epidemiologic studies of parkinsonism with special reference to the cohort hypothesis In: Gillingham FJ, Donaldson JM, eds. Proceedings of the Third Symposium on Parkinsonism. Edinburgh: E. and S. Livingstone, 1969: $12-16$

10. Jenkins AC. Epidemiology of parkinsonism in Victoria. Med J Aust 1966; $2 ; 496-502$.
11. Marttila RJ, Rinne UK. Epidemiology of Parkinson's disease in Finland. Acta Neurol Scand 1976; 53: 81-102.

12. Kessler II. Epidemiologic studies of Parkinson's disease. III. A community based survey. Am J Epidemiol 1972: 96: 242-254.

13. Schoenberg BS, Anderson DW. Haerer AF. Prevalence of Parkinson's disease in the biracial population of Copiah County, Mississippi. Neurology 1985; 35: 841-845.

14. Harada H, Nishikawa S, Takahashi K. Epidemiology of Parkinson's disease in a Japanese city. Arch Neurol 1983; 40: 151-154.

15. Li SC, Schoenberg BS, Wang CC, et al. A prevalence survey of Parkinson's disease and other movement disorders in the People's Republic of China. Arch Neurol 1985; 42: 655-657.

16. Kessler II. Parkinson's disease in epidemiologic perspective. In: Schoenberg BS, ed. Advances in Neurology, vol. 19, Neurological Epidemiology: Principles and Clinical Applications. New York: Raven Press, 1978: 355-384.

17. Kurland LT, Molgaard CA. The patient record in epidemiology. Sci Am 1981; 245: 54-63.

18. Kurland LT, Molgaard CA, Schoenberg BS. Mayo Clinic recordslinkage: contributions to neuroepidemiology. Neuroepidemiology 1982; 1: 102-114.

19. Schoenberg BS, Osuntokun BO, Adeuja AOG, et al. Abstract Comparison of the prevalence of Parkinson's disease in the rural U.S. and in rural Nigeria: door-to-door community studies. Neurology, in press.

20. Schoenberg BS. Clinical neuroepidemiology in developing countries: Neurology with few neurologists. Neuroepidemiology 1982; 1: 137-142.

21. Schoenberg BS. Neuroepidemiologic generalizations: High tax on importing data, low tax on importing principles. Neuroepidemiology $1983 ; 2$ : 117-120.

22. Barbeau A, Roy M, Cloutier T, et al. Environmental and genetic factors in the etiology of Parkinson's disease. In: Yahr MD, ed. Proceedings of the VIII International Symposium on Parkinson's Disease. New York: Raven Press, in press.

23. Lewin R. Parkinson's disease: An environmental cause? Science 1985; 229: 257-258.

24. Calne DB, Langston JW. Aetiology of Parkinson's disease. Lancet 1983; ii: $1457-1459$.

25. Rajput AH, Offord KP. Beard CM, et al. Epidemiology of parkinsonism: Incidence, classification, and mortality. Ann Neurol 1984; 16: 278-282.

26. Kurland LT, Kurtzke JF. Goldberg ID, et al. Parkinsonism. In: Kurland LT, Kurtzke JF. Goldberg ID, eds. Epidemiology of Neurologic and Sense Organ Disorders. Cambridge, Massachusetts: Harvard University Press, 1973: 41-63.

27. Hammond EC. Smoking in relation to the death rates of one million men and women. In Epidemiological Study of Cancer and Other Chronic Diseases, National Cancer Institute Monograph 19. Washington, D.C.: U.S. Government Printing Office, 1966: 127-204.

28. Kahn HA. The Dorn study of smoking and mortality among U.S. veterans; report on eight and one-half years of observation. In Epidemiologic Approaches to the Study of Cancer and Other Chronic Diseases, National Cancer Institute Monograph 19. Washington, D.C.: U.S. Government Printing Office, 1966: 1-125

29. Nefzger MD, Quadfasel FA, Kark VC. A retrospective study of smoking in Parkinson's disease. Am J Epidemiol 1968: 88: 149-158.

30. Kessler 11, Diamond EL. Epidemiologic studies of Parkinson's disease. I. Smoking and Parkinson's disease: A survey and explanatory hypothesis. Am J Epidemiol 1971: 94: 16-25.

31. Marttila RJ, Rinne UK. Smoking and Parkinson's disease. Acta Neurol Scand 1980; 62: 322-325.

32. Baumann RJ, Jameson HD, McKean HE, et al. Cigarette smoking and Parkinson's disease. I. A comparison of cases with matched neighbors. Neurology 1980; 30: 839-843.

33. Haack DG, Baumann RJ, McKean HE, et al. Nicotine exposure and Parkinson's disease. Am J Epidemiol 1981; 114: 191-200.

34. Ward CD, Duvoisin RC. Ince SE, et al. Parkinson's disease in 65 pairs of twins and in a set of quadruplets. Neurology 1983;33: 815-825.

35. Bharucha NE, Stokes L, Schoenberg BS, et al. A case-control study of twin pairs discordant for Parkinson's disease: A search for environmental risk factors. Neurology 1986: 36: 284-288. 
36. Rajput AH. Epidemiology of Parkinson's disease. Can J Neurol Sci 1984; 11. Suppl. 1: 156-160.

37. Todes CJ, Lees AJ. The pre-morbid personality of patients with Parkinson's disease. J Neurol Neurosurg Psychiatry 1985; 48: 97-100.

38. Eldridge R, Rocca WA. Parkinson disease: Etiologic considerations. In: King RA, Rotter JI, Motulsky AG, eds. The Genetic Basis of Common Disease. New York: McGraw-Hill, in press.

39. Duvoisin RC, Eldridge R, Williams A, et al. Twin study of Parkinson disease. Neurology 1981; 31: 77-80.

40. Rajput AH, Stern W, Christ A, et al. Abstract: Etiology of Parkinson's disease: environmental factors. Neurology 1984; 34, Suppl. 1: 207.

41. TannerCM. Abstract: Well water drinking and Parkinson's disease. Abstracts of the VIII International Symposium on Parkinson's Disease. New York: World Federation of Neurology Research Group on Extrapyramidal Diseases, 1985: 11.

42. Marttila RJ, Rinne U. Herpes simplex virus antibodies in patients with Parkinson's disease. J Neurol Sci 1978; 35: 375-379.

43. Elizan TS, Madden DL, Noble GR, et al. Viral antibodies in serum and CSF of parkinsonian patients and controls. Arch Neurol 1979; 36: 529-534.

44. Wetmore JG, Schwartz J, Elizan T. Nucleic acid homology studies of viral nucleic acid in idiopathic Parkinson's disease. Arch Neurol 1979; 36: 462-498.

45. Sasco AJ, Paffenbarger RS Jr. Measles infection and Parkinson's disease. Am J Epidemiol 1985; 122: 1017-1031.
46. Marttila RJ, Rinne UK. Arteriosclerosis, heredity and some previous infections in the etiology of Parkinson's disease. A casecontrol study. Clin Neurol Neurosurg 1977; 79: 46-56.

47. Poskanzer DC, Schwab RS. Cohort analysis of Parkinson's disease: evidence for a single etiology related to sub-clinical infection about 1920. J Chronic Dis 1963: 16: 961-973.

48. Geraghty JJ, Jankovic J, Zetusky WJ. Association between essential tremor and Parkinson's disease. Ann Neurol 1985; 329-333.

49. Jansson B, Jankovic J. Low cancer rates among patients with Parkinson's disease. Ann Neurol 1985; 17: 505-509.

50. Godwin-Austen RB, Lee PN, Marmot MG, et al. Smoking and Parkinson's disease. J Neurol Neurosurg Psychiatry 1982; 45: 577-581.

51. Burns RS, Lewitt PA. Pakkenberg H, et al. The clinical syndrome of striatal dopamine deficiency: MPTP-induced parkinsonism. N Engl J Med 1985; 312: 1418-1421.

52. Snyder SH. Clues to aetiology of Parkinson's disease from a toxin. Nature 1984; 311: 514-515.

53. Barbeau A, Roy M, Paris S, et al. Ecogenetics of Parkinson's disease: 4-hydroxylation of debrisoquine. Lancet 1985; ii: 1213-1215.

54. Eldridge R. Rocca WA, Ince SE. Parkinson's disease: Evidence against toxic etiology and for an alternative theory, $\ln$ : Markey SP, Castagnoli N, Trevor AJ, Kopin IJ, eds. MPTP: A Neurotoxin Producing A Parkinsonian Syndrome. New York: Academic Press, 1986: 355-367. 